\title{
O Especialista em Políticas Públicas e Gestão Governamental: um ensaio sobre a convergência de propósitos entre o processo seletivo e as atribuições legais
}

Rosane Maria Pio Silva

Universidade de Brasília (UnB)

\section{Andréa de Oliveira Gonçalves}

Universidade de Brasília (UnB)

A carreira de Especialista em Políticas Públicas e Gestão Governamental foi criada no final dos anos 1980 como forma de modernização dos quadros públicos e com a incumbência precípua de formular, implementar e avaliar políticas públicas, em graus diferentes de complexidade, responsabilidade e autonomia. A tarefa de delinear o perfil desse profissional de muitas competências não tem sido fácil à administração pública. Dessa forma, este ensaio se propõe a discutir a convergência de propósitos entre as seleções públicas e as atribuições legais. A partir da previsão legal, verificou-se que, entre os temas fundamentais a serem discutidos pelos candidatos, devem constar conceito de políticas públicas, ciclo político, modelos de análise, redes, modelos teóricos de administração pública e reformas administrativas. Os resultados demonstram pouca convergência entre as exigências nos primeiros certames, com aprimoramentos relevantes após 15 anos de criação da carreira, e os conhecimentos necessários ao exercício das atribuições legais.

Palavras-chave: Gestor Governamental, seleção pública, atribuições legais

[Artigo recebido em 27 de junho de 2016. Aprovado em 11 de abril de 2017.] 
El Especialista en Política Pública y Gestión de Gobierno: un ensayo sobre la convergencia de objetivos entre el proceso de selección y las obligaciones legales

La carrera de Especialista en Políticas Públicas y Gestión de Gobierno fue creada a finales de los años 1980 como una forma de modernizar la gestión pública y la tarea precipua de formulación, aplicación y evaluación de políticas públicas en los diferentes niveles de complejidad, responsabilidad y autonomía. La tarea de identificar este profesional de múltiples habilidades no ha sido fácil para la administración pública. Por lo tanto, este artículo se propone a discutir la convergencia de objetivos entre las selecciones públicas y obligaciones legales. A partir de la disposición legal, se observó que entre las cuestiones clave que deben ser discutidas por los candidatos deben de aparecer las de Concepto de Políticas Públicas, de Ciclo Político, de Modelos de Análisis, de Redes, de Modelos Teóricos de la Administración Pública y de Reforma Administrativa. Los resultados muestran poca convergencia entre los requisitos en los primeros concursos, con mejoras significativas después de 15 años de la creación de la carrera en relación con los conocimientos necesarios para llevar a cabo las obligaciones legales.

Palabras Clave: Gestor de Gobierno, selección pública, obligaciones legales

The Specialist in Public Policy and Government Management: a thesis on the convergence of purpose between the selection process and the legal assignments

The career in Public Policy specialist and Government Management was created in the late $80 \mathrm{~s}$ as a way to modernize public management and the essential task of formulating, implementing and evaluating public policies at different levels of complexity, responsibility and autonomy. The task of identifying this professional of many skills has not been easy for the public administration. Thus, this paper proposes to discuss the convergence of purposes between public selection processes and legal assignments. From the legal provision, it was found that among the key issues to be discussed by the candidates must appear Concept of Public Policy, Political Cycle, Analysis Models, Networks, Theoretical Models of Public Administration and Administrative Reforms. The results show little convergence between the requirements in the first examinations, with significant improvements after 15 years of the career creation in relation to the knowledge required for the performance of legal duties.

Keywords: Government Manager, public selection process, legal assignments 


\section{Introdução}

A renovação dos quadros superiores da administração pública, capazes de conferir apoio ao poder público na articulação de políticas concretas e práticas gerenciais modernas, depende da capacidade do Estado em recrutar servidores imbuídos dessas características.

O Governo Federal vem tentando, nos últimos anos, promover a contratação de pessoas com esse perfil. Algumas pesquisas apontam que esse atual movimento de recomposição de pessoal no setor público deve trazer melhorias gradativas ao desempenho institucional, inclusive pelo fato de que alguns dos servidores estão sendo selecionados por critérios meritocráticos, por meio de concursos públicos, que envolvem etapas de provas objetivas, provas discursivas, comprovação de experiência e exame de títulos (BARBOSA, 1996).

Um exemplo dessa modalidade de seleção é o provimento de vagas para o cargo de Especialista em Políticas Públicas e Gestão Governamental (EPPGG), mais conhecido como Gestor Governamental. De acordo com o Decreto no 5.176/2004, cabe a esse profissional o desenvolvimento de atividades de gestão governamental nos aspectos técnicos relativos à formulação, implementação e avaliação de políticas públicas, bem assim de direção e assessoramento em escalões superiores da administração pública federal direta, autárquica e fundacional, em graus variados de complexidade, responsabilidade e autonomia.

No tocante à carreira, foi criada com o ideal de profissionalização da alta gestão, demandando para tal servidores de visão generalista, capacidade de articulação, negociação de conflitos, mas principalmente com atribuições relativas à formulação, implementação e avaliação de políticas públicas.

Por determinação legal, esse profissional deve ser contratado via concurso público de provas e títulos, de livre concorrência, e passar por curso de formação específica. Porém, existem indícios de que a administração pública vem cumprindo o ritual da seleção - aplicação de prova objetiva e discursiva, mas ainda procura uma forma ideal para identificação do profissional capaz de aprimorar as ações do Estado, a exemplo das tantas alterações realizadas nos processos seletivos desde a sua criação.

Quando da primeira seleção, no ano de 1988, além das vagas abertas ao público, havia também reserva de vagas aos já servidores públicos federais, com algumas particularidades para ambos os concorrentes. Aos já servidores bastaria o ensino médio para concorrer, diferentemente dos demais, que deveriam ter curso superior. Em relação à idade, para os candidatos externos havia o limite de 35 anos, cobrança inexistente ao público interno (MARIA, 2000). 
Como forma de identificação do profissional com o perfil desejado e capacidade de gestão governamental, o certame previa, além das provas escritas, a análise curricular e a entrevista, realizada por diferentes profissionais, além da complementação da seleção via curso de formação de 2.800 horas.

$\mathrm{Na}$ seleção seguinte, realizada somente no ano de 1995, diversas dessas características foram alteradas. Todos os candidatos deveriam ter graduação, não havia vagas exclusivas para servidores públicos, e a etapa de entrevistas foi suprimida. A seleção se resumiu às provas objetivas e discursivas, mas com a alteração através da inclusão de prova de títulos com pontuação adicional para portadores do diploma de mestrado ou doutorado, como forma de valorização dos profissionais com alta qualificação acadêmica.

Em outras seleções, os candidatos deveriam fazer escolha por uma das áreas de opção do certame (educação, regulação, políticas públicas e outras). O formato das provas discursivas também foi sofrendo alterações, sendo em algumas edições em forma de resumo de texto, ou dissertação sobre determinado tema, ou estudo de caso, enfim, um processo relativamente inconstante.

A valorização da experiência gerencial só ocorreu a partir do 15으 ano de criação da carreira, em edital publicado no ano de 2003, em que candidatos que comprovassem o exercício de cargo ou função na administração pública ou privada teriam pontuação adicional por cada ano comprovado. Ao levar em consideração a atribuição legal do cargo de gestor, descrita como o profissional capaz de formular, implementar e avaliar políticas públicas, a administração pública aproximou o edital de seleção à identificação do profissional com experiência de cunho gerencial, fato que perdura desde então.

Em razão desses aprimoramentos para identificação de candidatos capazes de atender às atribuições legais, com curriculum profissional com perfil de gestão, foi que, na última seleção do ano de 2013, a pontuação para cada ano de experiência gerencial foi fortemente majorada. Por compreender que o candidato recémformado, sem maturidade profissional, teria dificuldades em lidar com a gestão de políticas, atuando em ambientes complexos e de interesses conflitantes, a Secretaria de Gestão (Seges/MPOG) do Ministério do Planejamento adotou um incremento significante na pontuação relativa à experiência em atividade gerencial, passando de 1,6 pontos (na seleção de 2009) para 15 pontos por cada ano comprovado (ESCOLA DE AdMINISTRAÇÃo FAZENDÁRIA - ESAF, 2013).

Por não haver apresentação no edital dos critérios para concessão de pontos, na percepção da associação que representa os gestores (Anesp), esse fato conferia livre arbítrio à banca para selecionar candidatos, de forma que a entidade impetrou 
ação judicial solicitando o cancelamento da seleção, fato acatado pelo Tribunal de Contas da União.

Assim, considerando as frequentes alterações nos processos seletivos, representando a busca da administração pública pelo aprimoramento das seleções e o êxito na modernização da gestão, este ensaio teórico se propõe a discutir qual a convergência de propósitos entre as etapas de provas do processo seletivo de Especialista em Políticas Públicas e Gestão Governamental com as atribuições legais requeridas para ingresso na carreira.

\section{Discussão teórica}

\section{Os 25 anos da carreira e o ambiente político-institucional}

As bases da crise do modelo weberiano, na opinião de Longo (2003), surgiram há muitos anos, com o próprio desenvolvimento do Estado de bem-estar, à medida que os governos foram assumindo cada vez mais a prestação de serviços, ganhando uma dimensão empresarial em sua forma de atuação. Em razão de uma nova crise do Estado, vivenciada no final dos anos 1980, surge a necessidade de outra reforma e reconstrução, que, segundo Bresser-Pereira (1996), acontece de forma acidentada e contraditória.

Nessa época, na visão de Coelho et al. (2011), se fortalecem as discussões anteriormente iniciadas, sobre o perfil do novo burocrata no processo de redemocratização no Brasil. Segundo os autores, "a (re)conquista dos direitos políticos e a ampliação dos direitos sociais (...) tornaram clara a necessidade de articulações no espectro político e profissionalização da alta burocracia para concretização das políticas públicas e modernização da gestão pública" (COELHO et al., 2011, p.181).

Na mesma corrente, Souza (2006) defende que a administração pública no Brasil vivenciava a urgência de um novo perfil de burocrata que não estava disponível nos quadros do serviço público vigentes à época.

Ciente dessa necessidade, o Presidente José Sarney encaminha para apreciação do Congresso Nacional o Projeto de Lei no 243/87, que previa a criação da carreira. A tramitação do projeto, segundo Maria (2000), não foi um processo pacífico. Em meio às turbulências, o curso de formação foi iniciado, em 1988, antes que a carreira estivesse efetivamente criada. O projeto sofreu modificações, entre elas a redução do número de vagas e limitações às atribuições inicialmente previstas. O fato é que somente em 1989 a carreira foi criada, pela Lei no 7.834/89, cujas atribuições legais compreendiam as 
atividades de formulação, implementação e avaliação de políticas públicas e de direção e assessoramento nos altos escalões da administração federal direta, autárquica e fundacional.

Para o sucesso do estabelecimento da carreira, o projeto de lei previa a contratação sucessiva de gestores, via abertura anual de concursos públicos, para promover não só a consolidação da carreira, mas também para gerar impactos imediatos nos padrões de gestão no Brasil (MAIA et al, 2012), o que, na prática, não aconteceu.

O primeiro concurso público foi realizado em 1988, para preenchimento de 120 vagas, sendo deixado totalmente de lado nos anos posteriores, durante todo o Governo Collor, momento em que nenhum processo seletivo foi aberto. Esse governo promoveu um primeiro baque à sua institucionalização. Logo após a posse dos primeiros gestores, formados em 1990, o governo extingue a carreira e reposiciona os gestores para o cargo de Analista de Orçamento.

No ano de 1995, o Governo Federal, sob a Presidência de Fernando Henrique Cardoso, cria o Ministério da Administração Federal e da Reforma do Estado (MARE) e, no mesmo ano, o Plano Diretor da Reforma do Aparelho do Estado (PDRAE), configurando o plano como "proposta explícita de inaugurar a chamada Administração Gerencial” (COSTA, 2008, p. 863).

Segundo Castor e José (1997), uma das iniciativas centrais era a criação de alguns núcleos, entre eles o Núcleo Estratégico, com o intuito principal de aperfeiçoar a capacidade de formulação, execução e controle de políticas públicas, contribuindo assim para maior nível de eficácia da máquina estatal.

Diante da necessidade de profissionais capazes de atender as demandas provenientes da ideologia gerencialista no setor público, o Governo FHC retoma os processos seletivos. Então, em 1995, acontece a abertura do 20 processo seletivo, com mudanças em relação ao primeiro. O objetivo era o de recrutar candidatos com sólidos conhecimentos acadêmicos, sendo permitida a concorrência apenas para portadores de diploma de nível superior, e com a realização da prova de títulos, na qual os candidatos com as maiores titulações (doutorado e mestrado) teriam pontos adicionais à sua nota final.

Nos anos seguintes (1996 a 1998), as seleções aconteceram com certa normalidade, como previa o projeto inicial. Em 1998 o governo publica a Lei no 9.625/98, promovendo redefinição nas atribuições legais do cargo, com a seguinte redação: "exercício de atividades de gestão governamental (grifo nosso), nos aspectos relativos à formulação, implementação e avaliação de políticas públicas", o que, na visão da Anesp (2014), representava uma tentativa de aproximação das atribuições com outras carreiras do serviço público federal, a saber, os ocupantes 
das carreiras de Finanças e Controle e Pesquisadores do Instituto de Pesquisa Econômica Aplicada (Ipea).

$\mathrm{Na}$ intercorrência do ano de 1998, o cronograma de seleções é quebrado. Segundo informações da Anesp (2014), por meio da publicação do Decreto no 2.983/99, o Governo Federal proibiu a realização de concursos no decorrer do ano, mas em seguida permitiu a retomada da quinta seleção, na qual foram ofertadas 140 vagas, seguidas de mais 90 decorrentes do 60 processo seletivo, aberto ao final do ano de 2000.

No ano de 2003, momento em que acontece a 8a seleção, havia outro pano de fundo político. Era o primeiro ano de mandato do Governo Lula, e, segundo Monteiro (2013), o Estado tinha novas diretrizes e prioridades na agenda governamental, relacionadas ao combate à concentração de renda, à riqueza e à exclusão social, assim como aos entraves à geração de emprego e renda no Brasil, o que refletiu no processo seletivo, especialmente pela inclusão do tema políticas públicas no conteúdo das provas discursivas, e pela pontuação adicional aos portadores de experiência profissional, aproximando o certame à realidade que o cargo de gestor requer.

No ano de 2004, o governo publica o Decreto $\mathrm{n}$ - 5.176, que regulamenta a carreira, estabelecendo novamente uma mudança nas atribuições, representando um acréscimo de atribuições acerca da responsabilidade dos gestores. Passa a vigorar o texto anterior relativo ao exercício de atividades de gestão governamental nos aspectos técnicos relativos à formulação, implementação e avaliação de políticas públicas, com a inclusão da expressão "em graus variados de complexidade, responsabilidade e autonomia". O decreto também previa um programa permanente de desenvolvimento, denominado Propeg, objetivando o aprimoramento da formação de gestores, além da definição de critérios para solicitação, concessão e renovação de afastamentos.

Em 2005, o Ministério do Planejamento autoriza a realização do 9o processo seletivo para 150 vagas, distribuídas igualmente entre as áreas de Regulação e Gestão de Políticas Públicas, apesar de figurarem praticamente os mesmos temas do certame anterior.

Como fortalecimento das escolas de governo, Torres (2012) destaca o Decreto no 5.707/06, que instituiu diretrizes para o desenvolvimento de pessoal na administração pública federal, como importante instrumento de fomento para ações de qualificação pessoal. No ano seguinte, segundo levantamento feito pela Agência Española de Cooperación Internacional para El Desarrollo - AECID (2009), a Seges constituiu um grupo de trabalho com intuito de elaborar proposta de regimento para a carreira. 
Em 2008, ano da 10a seleção, as vagas foram distribuídas entre duas novas áreas de opção, Gestão Governamental ou Políticas Públicas, com mudanças nas discursivas, esclarecendo o edital que a abordagem da prova seria relativa aos desafios para a formulação, implementação e acompanhamento das políticas públicas, trazendo assim uma modificação no perfil dos novos gestores. Nesse ano, a Lei no 11.890 é editada com o intuito de restabelecer remuneração através de subsídio para carreiras do Executivo, gerando como efeito a perda de importância das avaliações individuais de desempenho, fragilizando o mecanismo de gestão de recursos humanos introduzido na modernização prevista no PDRAE.

No ano seguinte, 2009, é aberto o último edital do Governo Lula, com algumas alterações, a exemplo da retirada das áreas de opção, mas com relevantes aprimoramentos nas provas discursivas, representando um avanço na avaliação do conhecimento teórico que os candidatos deveriam apresentar sobre conteúdos relativos à gestão e políticas públicas, além da simples marcação de respostas nas provas objetivas. Assim, no período de oito anos do Governo Lula, foram realizadas quatro seleções, quebrando o cronograma de contratações anuais previsto na criação. A Anesp (2014) ressalta a relevante valorização salarial ocorrida no intervalo entre os anos de 2003 a 2010, saindo a remuneração de pouco mais de R\$ 2 mil reais para quase $R \$ 13$ mil, o que representa um crescimento real bem superior à inflação do período, interpretado como importante valorização da carreira.

No Governo Dilma, iniciado em 2011, Silva (2014) afirma que não existia uma agenda de gestão pública ampla e bem definida, mas era possível identificar a presença de novas estratégias, como da Câmara de Políticas de Gestão, Desempenho e Competitividade (CGDC) e da intensificação da influência do Movimento Brasil Competitivo ( $\mathrm{MBC}$ ), trazendo consigo uma série de consultorias aos órgãos da administração pública federal. O autor destaca que o intuito da Câmara era o de atuar sobre alguns dos gargalos da gestão pública federal, "através da formulação de políticas e medidas específicas destinadas à racionalização do uso dos recursos públicos e o aperfeiçoamento da gestão pública" (SILVA, 2014, p. 6).

Segundo a Anesp (2014), o período do governo da Presidente Dilma é marcado por divergências entre a associação e o órgão supervisor da carreira, a Seges/MPOG, principalmente por discordância às ações relativas à mobilidade, à capacitação e inclusive ao processo de seleção de EPPGG. Em relação às seleções, nesse governo houve a abertura de apenas uma seleção, no ano de 2013, posteriormente cancelada pelo TCU, de forma que nesse governo nenhum processo seletivo chegou a ser concretizado.

Assim, pode-se inferir que a carreira é pautada por diferenças entre o projeto de criação e o seu desenvolvimento. Na prática, as seleções que deveriam ocorrer com 
certa regularidade não aconteceram, alguns governos não valorizaram o projeto, a institucionalização da carreira não é fato concreto, os requisitos dos editais são distintos e inconstantes. Na fala de Santos e Cardoso (2000, p. 12), "ao longo da trajetória da carreira, o modelo original foi bastante modificado, perdendo algumas de suas características, devido à influência de grupos de pressão, outras carreiras e instituição do governo central".

E, como principal aspecto, há relativa indefinição das atribuições legais no exercício da prática dos gestores, no que concerne à capacidade de formular, implementar e avaliar políticas públicas em graus diferentes de complexidade e responsabilidade, como retratado em tópico seguinte.

\section{A carreira e suas atribuições legais}

O processo de implantação da carreira, que inicialmente designou os membros como Técnicos em Políticas Públicas e Gestão Governamental (no projeto de lei), foi alterado recebendo posteriormente a denominação de Especialista em Políticas Públicas e Gestão Governamental, presente na Medida Provisória no 84 de setembro de 1989.

No ano de 2004, as atribuições dos gestores foram regulamentadas pelo Decreto no 5.176 e relatadas pela entidade que gerencia a carreira, conforme descrito no Quadro 1. 


\section{Quadro 1 - Atribuições legais}

Legislação
Medida Provisória no 84,
de 15 de setembro/1989
e
Lei no 7.834, de 06 de
outubro/1989
Decreto no 5.176/2004
Comunicado Seges/MPOG
04, de abril/2010

Disposições/Atribuições

Cria a carreira e os respectivos cargos de Especialistas em Políticas Públicas e Gestão Governamental e dá outras providências.

Atribuições: execução de atividades de formulação, implementação e avaliação de políticas públicas, bem assim de direção e assessoramento em escalões superiores da administração direta e autárquica.

Regulamenta a carreira de Especialista em Políticas Públicas e Gestão Governamental (EPPGG) e dá outras providências.

Atribuições: atividades de gestão governamental nos aspectos técnicos relativos à formulação, implementação e avaliação de políticas públicas, bem assim de direção e assessoramento em escalões superiores da administração pública federal direta, autárquica e fundacional, em graus variados de complexidade, responsabilidade e autonomia (grifo nosso).

Possui atribuições amplas relacionadas à formulação, implementação e avaliação de políticas públicas e ao aprimoramento da organização e do funcionamento da máquina governamental.

Fonte: Lei no 7.834/89, Decreto no 5.176/2004, Seges/MPOG.

A definição das atribuições dos EPPGGs, segundo Cheibub e Mesquista (2001), apontava preferencialmente para a gestão de políticas (atividade meio) e, subsidiariamente, para o desenvolvimento de atividades finalísticas de formulação, implementação e avaliação de políticas pública, o que gerou na verdade uma certa indefinição nas atribuições primordiais dos gestores. Afinal, são as atividades meio (gestão) ou atividades fins (formulação de políticas públicas)?

Em razão da não existência de outros documentos legais que retratem pormenorizadamente as atribuições dos gestores, optou-se pela apresentação de discussões teóricas realizadas por estudiosos da carreira, a fim de promover maior compreensão sobre o perfil profissional que o cargo requer.

A análise desses estudos permitiu a identificação de percepções para competências semelhantes, particularmente aquelas relacionadas à execução de políticas públicas e seu acompanhamento, determinando necessidade de conhecimentos aprofundados sobre o tema. 


\section{Quadro 2 - Atribuições teóricas}

\begin{tabular}{ll} 
Estudo & Perfil desejado \\
& $\begin{array}{l}\text { Especialista em comando, com aptidão para encontrar } \\
\text { o conhecimento técnico especializado necessário à } \\
\text { execução das políticas públicas, aliada à capacidade } \\
\text { e domínio das técnicas de negociação, promovendo } \\
\text { motivação junto às equipes de trabalho, bem assim } \\
\text { planejando e coordenando suas ações (grifo nosso). }\end{array}$ \\
\hline Cantos e Cardoso (2000) & $\begin{array}{l}\text { Cabidade de negociação, coordenação e articulação, } \\
\text { mobilizaço intra e intergovernamental. }\end{array}$ \\
Cruz (2009) & $\begin{array}{l}\text { Visão estratégica das políticas públicas e de suas } \\
\text { relações com a organização e funcionamento da } \\
\text { administração pública e conhecimento teórico e prático } \\
\text { dos problemas de governo e das políticas públicas (grifo } \\
\text { nosso). }\end{array}$ \\
\hline Capacidade de análise das políticas de Estado. \\
Ruedes (2012)
\end{tabular}

Fonte: Santos e Cardoso (2000); Cruz (2009); Guedes (2012); Reis, Ferrarezi e Antico (2012).

Tal percepção sobre a relação direta das atribuições executadas pelos profissionais com a gestão de políticas públicas está também descrita em documento elaborado por grupo de trabalho da Anesp, constituído no ano de 2008, prevendo como competências iniciais a "prestação de assistência técnica direta a diretores e gerentes de programas e ações governamentais, na implementação e avaliação de políticas públicas" (AsSOCIAÇÃo NACIONAL dos ESPECIALISTAS EM POLÍTICAS PúBLICAS E GESTÃo GOVERNAMENTAL, 2009).

Como proposta de aprimoramento, decorrente do projeto de Modernização da Gestão Pública, a AECID (2009) apresentou à Secretaria de Gestão que acompanha o desenvolvimento da carreira (Seges/MPOG) um documento de consolidação de diversos aspectos relativos ao cargo, entre eles o perfil desejado, que retrata funções específicas a serem exercidas de acordo com a Figura 1 . 0 estudo apresenta 
especificações de como os gestores podem se desincumbir de todas essas funções nas etapas do ciclo da gestão das políticas públicas, o que expressa a necessidade de conhecimento por parte dos concorrentes ao cargo sobre o alcance das políticas e a máquina governamental.

\section{Figura 1 - Ciclo político}

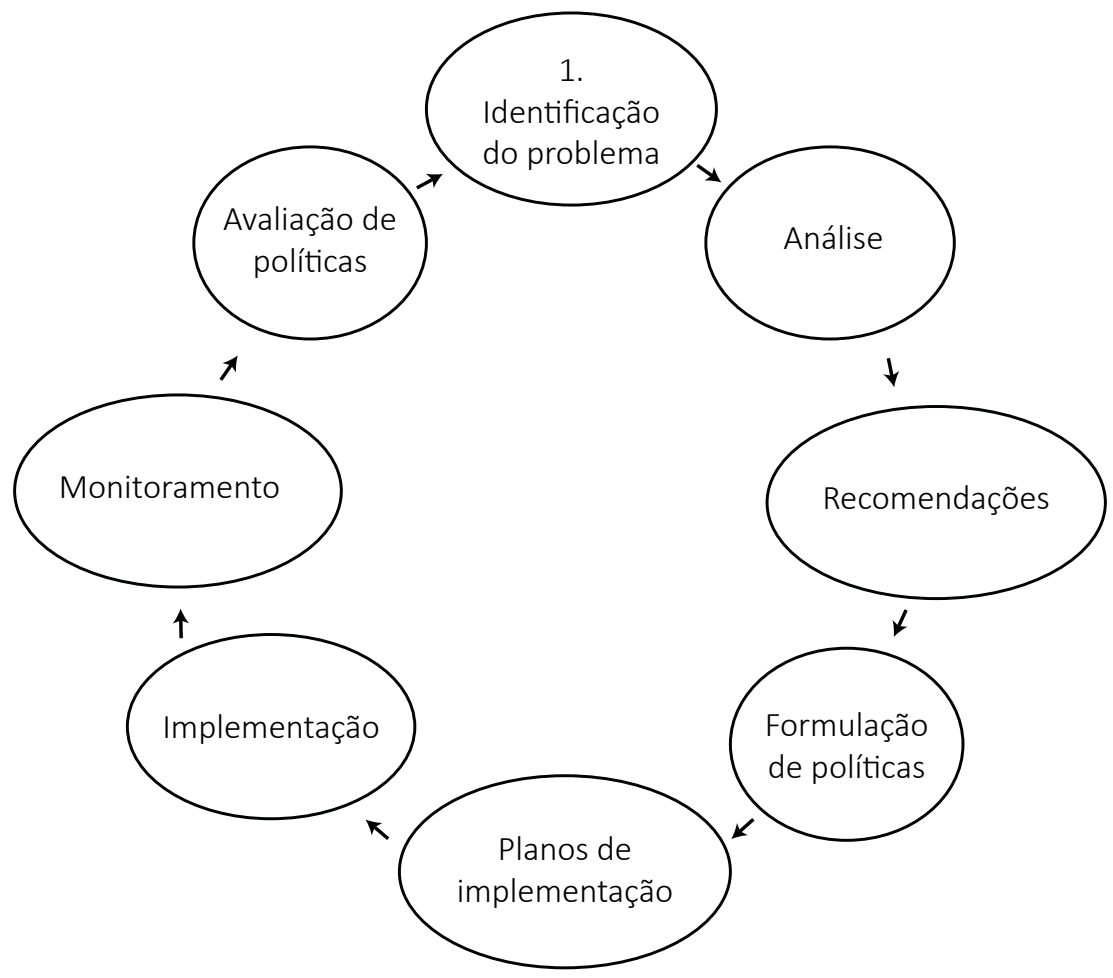

Fonte: AECID (2009).

Em suma, os estudos indicam que esse profissional deve ser policompetente, com visão de Estado e ciente de sua importância para realização de políticas públicas que se viabilizem em forma de melhoria na prestação de serviços públicos, fato passível de concretização mediante a convergência das seleções aos aspectos relativos às atribuições legais que o cargo requer.

Assim, partindo do texto da previsão legal, associado à percepção dos estudiosos sobre o perfil desejado, e aplicando a técnica de análise de conteúdo de Bardin (2010), infere-se que as dimensões teóricas 'políticas públicas' e 'administração pública' podem ser caracterizadas como conhecimentos fundamentais a serem exigidos nas provas de seleção por apresentarem relação direta às atribuições legais, não descartando a exigência de outros conteúdos. 
Para melhor compreensão e apoio ao estabelecimento de vertentes temáticas passíveis de cobrança nos processos seletivos, buscou-se fundamentação literária sobre as dimensões citadas. Esse suporte teórico sugere que a abordagem à dimensão políticas públicas demanda dos candidatos os conhecimentos relativos aos conceitos de redes de políticas, modelos de análise e especialmente o ciclo de políticas públicas, por envolver a compreensão de problemas, discussão de alternativas, formas de implementação, monitoramento e avaliação de políticas, conforme Quadro 3.

\section{Quadro 3 - Suporte teórico para políticas públicas}

\section{Dimensão teórica: políticas públicas}

Aspectos gerais: uma política pública é uma diretriz elaborada para enfrentar um problema público. Orientação ou passividade também fazem parte das políticas públicas.

Demanda a compreensão objetiva de processos e estruturas na elaboração e execução de políticas públicas, os quais ocorrem em um ambiente político de crescente fluidez institucional (PROCOPIUCK, 2013).

\begin{tabular}{llll}
\hline Tipologias de PP & Redes de políticas & $\begin{array}{l}\text { Ciclo de políticas } \\
\text { públicas }\end{array}$ & $\begin{array}{l}\text { Modelos de } \\
\text { análise }\end{array}$ \\
\hline Distributivas & Redes & $\begin{array}{l}\text { Identificação do } \\
\text { problema }\end{array}$ & $\begin{array}{l}\text { Multiple streams } \\
\text { (múltiplos fluxos) }\end{array}$ \\
Regulatórias & Atores sociais & $\begin{array}{l}\text { Formação da } \\
\text { agenda }\end{array}$ & Garbage can \\
Redistributivas & Arenas decisórias & $\begin{array}{l}\text { Formulação de } \\
\text { alternativas }\end{array}$ & (lata de lixo) \\
& & $\begin{array}{l}\text { Punctuated } \\
\text { equilibrium }\end{array}$ \\
& & Implementação & Coalition \\
& & Avaliação & advocacy
\end{tabular}

Autores consultados: Dye (1972)/ Lynn (1980)/Brooks (1989)/Mead (1995) in Souza (2006); Rua (2009); Procopiuck (2013); Secchi (2009); Capela (2006); Calmon (2013); Kingdon (1995); Pedroso (2013).

Fonte: Elaboração própria.

No âmbito da dimensão administração pública, a exigência de conhecimentos envolve a compreensão dos modelos teóricos e a das principais reformas administrativas no contexto brasileiro. 


\section{Quadro 4 - Suporte teórico para a dimensão administração pública}

\section{Dimensão teórica: administração pública}

Aspectos gerais: a administração pública brasileira é marcada por diferentes modelos e processos de reformas, estabelecidos através de transformações institucionais do aparelho do Estado, que visam à superação das dificuldades gerenciais do setor público. Esses modelos de administração pública são definidos como: patrimonialista, burocrático e gerencial.

\section{Patrimonialista}

Extensão do poder do soberano para a coisa pública

Nepotismo frequente

Bens públicos utilizados em benefício do governante

\section{Corrupção}

Irrelevante preocupação com demandas sociais
Burocrático

Max Weber

Pouca ênfase em resultados

Rígida hierarquia funcional

Princípios de profissionalização

Centralizador e autoritário

Exercício do cargo público via processos de seleção

Baixa orientação para demandas dos cidadãos

Crise do modelo

\section{Gerencial}

Busca pela eficiência da AP

Poucos níveis hierárquicos

Descentralização administrativa

Qualidade dos serviços

Gestão do patrimônio

Emprego eficaz do dinheiro público

Cumprimento de metas

Controle de resultados

Formas flexíveis de gestão

Reformas administrativas: Reforma de 30; Decreto-Lei no 200/67, Plano Diretor de Reforma do Estado - PDRAE (1995).

Autores consultados: Weber (1994); Bresser-Pereira (1996, 1998, 2005); Abrúcio (2007); Paes de Paula (2005); Fadul e Souza (2005); Matias-Pereira (2008), Denhardt (2012).

Fonte: Elaboração própria. 
Dessa forma, tomando-se por base os conhecimentos que deveriam compor a relação de conteúdos exigidos, convergentes às atribuições legais previstas para o cargo, discorre a análise sobre o conteúdo das seleções, a fim de identificar a proximidade entre os conhecimentos solicitados e aqueles compreendidos como fundamentais aos candidatos que almejam o ingresso na carreira.

\section{Análise dos processos de seleção}

\section{Dos primeiros quinze anos de carreira}

O primeiro processo seletivo para o cargo foi realizado no final dos anos 1980, especificamente no ano de 1988. O Quadro 5 apresenta as características gerais e exigências do $1^{\text {o }}$ edital. Nota-se que, apesar de a seleção ter sido para servidores que teriam sob sua responsabilidade a formulação, implantação e avaliação de políticas públicas, os temas da prova objetiva e discursiva não faziam referência aos temas administração pública ou políticas públicas.

Outro item a ser destacado diz respeito ao fato de que, à época, o primeiro processo de seleção não exigia o nível de graduação aos concorrentes servidores públicos, o que inviabilizava completamente a cobrança de conhecimentos aprofundados de políticas públicas e/ou administração pública, fato corroborado pelos conteúdos cobrados nas provas objetivas, quase todos exigindo apenas noções dos temas elencados. 


\section{Quadro 5 - Requisitos previstos no 10 concurso de gestor}

\begin{tabular}{|c|c|}
\hline Ano & $1987 / 88$ \\
\hline $\begin{array}{l}\text { Instituição } \\
\text { responsável }\end{array}$ & Fundação Cesgranrio \\
\hline $\begin{array}{l}\text { 1a fase de provas } \\
\text { objetivas (de caráter } \\
\text { eliminatório) }\end{array}$ & $\begin{array}{l}\text { 1. História Econômica } \\
\text { 2. Noções de Administração } \\
\text { 3. Noções de Economia } \\
\text { 4. Noções de Ciência Política } \\
\text { 5. Noções de Direito }\end{array}$ \\
\hline $\begin{array}{l}\text { 2a fase de provas } \\
\text { discursivas (de } \\
\text { caráter eliminatório) }\end{array}$ & $\begin{array}{l}\text { Duas provas sobre questões nacionais e internacionais, } \\
\text { com enfoque administrativo, econômico, político e jurídico. } \\
\text { Prova de língua portuguesa e língua estrangeira (inglês ou } \\
\text { francês) }\end{array}$ \\
\hline $\begin{array}{l}\text { 3a fase } \\
\text { (classificatório) }\end{array}$ & Entrevistas e análise curricular \\
\hline Prova de títulos & Não previa \\
\hline Reserva de vagas & $\begin{array}{l}50 \% \text { das vagas destinadas para candidatos já servidores } \\
\text { públicos e sem limite de idade. Outros } 50 \% \text { para público } \\
\text { externo, com idade máxima de } 35 \text { anos e ensino superior } \\
\text { completo }\end{array}$ \\
\hline $\begin{array}{l}\text { 2a fase - curso de } \\
\text { formação }\end{array}$ & $\begin{array}{l}18 \text { meses, divididos em fases de embasamento, estágio e } \\
\text { complementação, num total de } 2.800 \text { horas }\end{array}$ \\
\hline
\end{tabular}

Fonte: Edital Funcep/Cesgranrio - Diário Oficial da União (1987).

Após a realização do primeiro concurso, e, apesar de previsto na descrição da carreira que as seleções aconteceriam anuais, somente em 1995 o 20 concurso foi aberto, seguido por três outros, até 1998. Nesse momento da 2 a seleção, o pano de fundo político havia se alterado. O Brasil vivenciava a implantação de uma nova reforma e a adoção do Plano Diretor da Reforma do Aparelho do Estado, cuja proposta era de adotar a chamada Administração Gerencial. Esses fatos alteraram a exigência sobre os conhecimentos esperados dos candidatos e, com elas, houve mudanças no edital.

O Quadro 6 apresenta as primeiras modificações, entre tantas que as seleções vêm passando desde sua criação. Foram inclusas provas de títulos, de forma que 
candidatos portadores de mestrado e doutorado receberam pontos adicionais, demonstrando um perfil mais acadêmico para os gestores contratados na segunda metade dos anos 1990, e um perfil diferenciado dos aprovados no primeiro processo, em que o nível superior nem era exigido aos já servidores. Por outro lado, o curso de formação sofreu elevada redução em relação à primeira turma, passando de 2.800 horas, para pouco mais de 1.000 horas.

Em relação ao conteúdo, verificou-se maior proximidade entre os temas exigidos e aqueles descritos como fundamentais, citados no Quadro 3. A análise detalhada do edital de seleção permite relatar que foram cobrados conhecimentos relativos à estruturação da máquina administrativa no Brasil, à trajetória do modelo racional-legal, ao paradigma pós-burocrático, aproximando a exigência de conhecimentos aos aspectos relativos aos modelos teóricos e às características da administração pública no Brasil. Sobre o tema políticas públicas e quaisquer de suas categorias (conceito, fases, modelos de análise), praticamente nenhum conhecimento foi exigido.

\section{Quadro 6 - Requisitos previstos no 20 concurso de gestor}

\section{Ano}

Instituição responsável

1a fase de provas objetivas (de caráter eliminatório)

\section{5}

\section{Escola de Administração Fazendária (Esaf)}

1. Economia

2. Administração Pública (com Administração, Direito Constitucional e Administração e Ciência Política)

3. Língua Inglesa

4. Língua Portuguesa

5. Raciocínio matemático

Provas discursivas (de caráter eliminatório)

Redação sobre tema no domínio de Administração Pública

Não previa

Pontos adicionais (20 ou 15) para portadores de título de Prova de títulos doutorado, (10 ou 5 pontos) para portadores de título de mestrado

2a fase - curso de formação
6 meses, dividido em duas etapas: o curso de formação propriamente dito, seguido do ciclo de atividades $=$

Fonte: Edital Esaf (1995). 
No concurso posterior, do ano de 1996, uma terceira banca examinadora é contratada, ficando a seleção sob a responsabilidade da Fundação Carlos Chagas. Junto a ela, outras mudanças surgem no edital. Os candidatos, ao efetivarem inscrição no concurso, deveriam informar opção por três áreas distintas: Gestão Econômica, Gestão Pública ou Políticas Sociais, mas a exigência sobre o conhecimento do candidato sobre os respectivos temas era relativamente baixa. Para lograr aprovação, o candidato deveria obter, em média, apenas $30 \%$ de acerto nas provas, sem a exigência de algum percentual mínimo no conjunto de provas.

Uma análise mais detalhada sobre os temas cobrados não foi possível, visto que o edital não trouxe a descrição dos conteúdos constantes de cada uma das disciplinas, citando apenas as grandes áreas: Inglês, Português e Raciocínio Lógico para todos; Administração Pública e Economia para as opções de Gestão Econômica ou Pública; e Sociologia, Educação, Serviço Social e Economia para optantes de Políticas Sociais, impossibilitando analisar a proximidade dos conhecimentos exigidos àqueles descritos no Quadro de Referência, mas, de forma geral, deixando indícios de que o tema políticas públicas novamente não foi retratado.

No 4ำ processo seletivo, em 1997, os candidatos deveriam fazer opção por qual tema responderiam às questões objetivas, entre elas Economia, Educação ou Administração Pública. 
Tabela 1 - Distribuição de temas do 4ำ processo seletivo

\begin{tabular}{|c|c|c|c|c|}
\hline Área & Disciplinas & $\begin{array}{l}\text { No de } \\
\text { questões }\end{array}$ & Peso & $\begin{array}{c}\% \\
\text { mínimo }\end{array}$ \\
\hline \multirow{7}{*}{$\begin{array}{l}\text { Com área de escolha } \\
\text { para realização da } \\
\text { prova objetiva (entre } \\
\text { as áreas descritas } \\
\text { nos conhecimentos } \\
\text { específicos) }\end{array}$} & Conhecimentos gerais & & & \multirow{7}{*}{$\begin{array}{l}\text { em } \\
\text { todas }\end{array}$} \\
\hline & Língua Portuguesa & 16 & 1 & \\
\hline & Língua Inglesa & 16 & 1 & \\
\hline & $\begin{array}{l}\text { Raciocínio Lógico - } \\
\text { Quantitativo }\end{array}$ & 16 & 1 & \\
\hline & & & 1 & \\
\hline & $\begin{array}{l}\text { Fundamentos de } \\
\text { Economia }\end{array}$ & 16 & 1 & \\
\hline & $\begin{array}{l}\text { Fundamentos de Adm. } \\
\text { Pública }\end{array}$ & 16 & & \\
\hline \multirow[t]{11}{*}{ Provas objetivas } & Específicos & 40 & 2 & 30,0 \\
\hline & Economia & & & \\
\hline & Educação (que inclui): & 20 & 2 & 30,0 \\
\hline & - $\quad$ Educação no Brasil & 12 & 2 & 30,0 \\
\hline & - Ciência Política & 08 & 2 & 25,0 \\
\hline & $\begin{array}{ll}\text { - } & \text { Dir. Const/ } \\
& \text { Administrativo }\end{array}$ & & & \\
\hline & $\begin{array}{l}\text { Administração Pública } \\
\text { (inclui): }\end{array}$ & & & \\
\hline & - $\quad$ Administração & 14 & 2 & 28,5 \\
\hline & - Ciência Política & 10 & 2 & 30,0 \\
\hline & $\begin{array}{ll}\text { - } & \text { Dir. Const/ } \\
& \text { Administrativo }\end{array}$ & 08 & 2 & 25,0 \\
\hline & $\begin{array}{l}\text { - Economia do St. } \\
\text { Público }\end{array}$ & 08 & 2 & 25,0 \\
\hline
\end{tabular}

Prova discursiva Prova oral/Entrevista Prova de títulos
Redação valendo 20 pontos, sendo obrigatório 30\% de acerto; Não previa Máximo de 20 pontos, para portadores de título de doutorado

Fonte: Edital FCC (1997). 
Em análise detalhada ao edital, e aos conteúdos que compunham cada um dos temas, não se identificou a exigência de conhecimentos relativos a políticas públicas, a não ser algum conceito de redes de políticas, pela cobrança do conteúdo "atores, arenas decisórias e intermediação de interesses" (EDITAL FCC, 1997), e nada além.

No 5o concurso, do ano de 1998, a banca examinadora foi mantida e as características da seleção foram praticamente as mesmas, com exceção de uma nova área de opção ao candidato para realização da prova de conhecimentos específicos, de modo que, além daquelas previstas no ano anterior, o tema Saúde passou a vigorar entre os demais.

A comprovação de conhecimentos aprofundados da capacidade argumentativa, construtiva e crítica por parte do candidato foi bastante superficial, considerando que a prova dissertativa se resumiu à síntese de um texto, com valor total de 20 pontos, bastando ao candidato a obtenção de 6 para sua classificação. Como não havia a exigência de pontuação geral para aprovação, cumpridos os quantitativos mínimos em cada conteúdo, a classificação final do candidato era dada pelo somatório dos pontos obtidos nas duas etapas do concurso.

Acerca da análise dos conteúdos, especificamente no quesito Fundamentos de Administração Pública e Administração, foi identificada a exigência de conteúdos relativos às formas históricas: patrimonialismo e administração burocrática racional-legal; a crise do modelo burocrático; administração pública gerencial e a nova administração pública, o que determina a aproximação do conhecimento exigido à realidade administrativa no Brasil, mas permanecendo a inexistência de temas relativos às políticas públicas, mesmo no aspecto conceitual.

Em 2000, ano do 6ㅇ processo seletivo, a organização voltou à responsabilidade da Escola Fazendária (Esaf). Nessa nova seleção, mudanças foram implementadas: a retirada das áreas de opção para realização de provas objetivas, redução de conteúdos e aumento da pontuação mínima para aprovação em cada um dos temas, conforme descrito na Tabela 2. O edital permaneceu não fazendo menção a conteúdos relativos ao tema políticas públicas, afastando a seleção da identificação de profissionais com conhecimentos sobre políticas sociais, articulação política e suas vertentes. 
Tabela 2 - Distribuição de temas do 60 processo seletivo

\begin{tabular}{|c|c|c|c|}
\hline Área & Disciplinas & $\begin{array}{l}N^{0} \text { de } \\
\text { questões }\end{array}$ & Peso \\
\hline
\end{tabular}

\section{TIPO 1}

Língua Portuguesa

Língua Inglesa

Sem área de escolha

Raciocínio Lógico -

Quantitativo

Dir. Constitucional e

Administrativo
20

05

10

15

1

$40 \%$ do

total

de 50

pontos

possíveis

Provas objetivas

\section{TIPO 2}

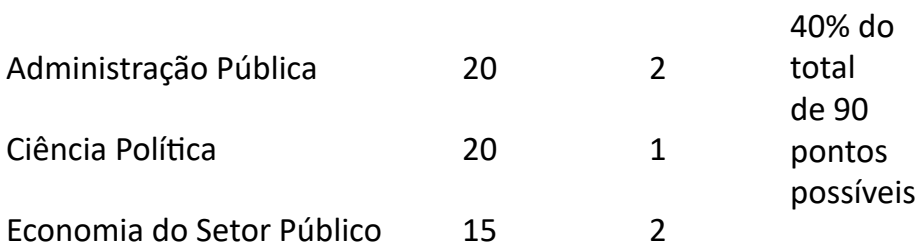

Prova discursiva

Desenvolvimento de dois temas relacionados ao conteúdo das provas do Tipo 2 , totalizando 40 pontos, e pontuação mínima de $40 \%$

Fonte: Edital Esaf (2000).

No quesito prova discursiva, houve avanço, visto que nessa seleção o candidato deveria desenvolver uma produção textual sobre dois dos três temas específicos, representando uma avaliação mais detalhada, bem diferente do concurso anterior, em que era o bastante o resumo de um único texto.

Em 2001 acontece o 70 edital de seleção, mantendo-se os mesmos temas. Sobre a exigência dos conhecimentos, os $40 \%$ necessários na seleção anterior voltam ao patamar de $30 \%$ de acertos mesmo para os temas enquadrados como específicos (Direito, Administração Pública, Ciência Política e Economia do Setor Público). $\mathrm{Na}$ análise dos temas, a não ser pelo conteúdo relativo ao "processo de decisão em políticas públicas; atores e arenas decisórias", não há menção sobre políticas públicas, nem solicitação de conceito ou suas fases.

Esse fato de conteúdos praticamente idênticos entre uma seleção e outra, nenhuma menção ao cerne das atribuições relativas à gestão de políticas, todo o processo moldado sem inovações, acabava por conferir vantagem aos chamados 
"concurseiros", pela previsibilidade de contexto e questões, através da análise histórica de provas anteriores.

\section{As seleções após o 15 ano da carreira}

Em 2003, a 8a seleção acontece em outra realidade política. Era o primeiro ano do Governo Lula, o Estado tinha novas diretrizes e prioridades na agenda governamental, especialmente aquelas relacionadas ao combate à concentração de renda e à exclusão social, assim como os entraves à geração de emprego. Nesse contexto, a Secretaria de Gestão, juntamente à Escola Fazendária, percebem a necessidade de mudanças no processo seletivo. Assim, nessa seleção e na posterior, do ano de 2005, o candidato era demandado a fazer opção por áreas de escolha, sendo Economia, Infraestrutura ou Social na oitava seleção, e Regulação ou Gestão/ Políticas Públicas na nona, momento em que concretamente o tema políticas públicas entra como exigência de conhecimento, conforme comparação descrita no Quadro 8.

Em análise aos requisitos destes novos processos seletivos, observou-se que, somente após 15 anos de criação da carreira as questões relativas ao eixo central do cargo de gestor surgem como conhecimento necessário a ser comprovado, apesar de tal cobrança ocorrer apenas na prova discursiva. 
Quadro 7 - Comparativo de disciplinas dos concursos dos anos 2000

\begin{tabular}{|c|c|c|}
\hline Concurso 2001 & Concurso 2003 & Concurso 2005 \\
\hline $\begin{array}{l}\text { Conhecimentos } \\
\text { gerais: }\end{array}$ & $\begin{array}{l}\text { Conhecimentos gerais e } \\
\text { específicos: }\end{array}$ & $\begin{array}{l}\text { Conhecimentos gerais: } \\
\text { Língua Portuguesa }\end{array}$ \\
\hline Língua Portuguesa & Língua Portuguesa & Língua Inglesa \\
\hline Língua Inglesa & Língua Inglesa & Raciocínio Lógico- \\
\hline $\begin{array}{l}\text { Raciocínio Lógico- } \\
\text { Quantitativo }\end{array}$ & $\begin{array}{l}\text { Raciocínio Lógico- } \\
\text { Quantitativo }\end{array}$ & Quantitativo \\
\hline & $\begin{array}{l}\text { Direito Const./ } \\
\text { Administrativo }\end{array}$ & Direito Const./Administrativo \\
\hline $\begin{array}{l}\text { Conhecimentos } \\
\text { específicos: }\end{array}$ & Teoria Política Aplicada & $\begin{array}{l}\text { Conhecimentos } \\
\text { especializados: }\end{array}$ \\
\hline $\begin{array}{l}\text { Direito Constitucional } \\
\text { e Administrativo }\end{array}$ & $\begin{array}{l}\text { Fundamentos de } \\
\text { Economia }\end{array}$ & Teoria Política \\
\hline $\begin{array}{l}\text { Administração Pública } \\
\text { Economia do Setor } \\
\text { Público }\end{array}$ & Gestão Pública & Conhecimentos específicos: \\
\hline Ciência Política & & $\begin{array}{l}\text { Teoria Econômica } \\
\text { Estado e Gestão Pública }\end{array}$ \\
\hline Prova discursiva: & Prova discursiva: & Prova discursiva: \\
\hline $\begin{array}{l}\text { Sobre quaisquer dos } \\
\text { temas relacionados } \\
\text { aos conhecimentos } \\
\text { específicos da prova } \\
\text { objetiva }\end{array}$ & $\begin{array}{l}\text { relacionada à área de } \\
\text { opção: } \\
\text { Área I: Teoria Econômica } \\
\text { e Políticas Publicas } \\
\text { Área II: Infraestrutura e } \\
\text { Políticas Públicas } \\
\text { Área III: Políticas Sociais } \\
\text { no Brasil e Políticas } \\
\text { Públicas }\end{array}$ & $\begin{array}{l}\text { relacionada à área de opção: } \\
\text { Área I: Estado e Gestão } \\
\text { Pública e Políticas Publicas } \\
\text { Área II: Estado e Gestão } \\
\text { Pública e Regulação }\end{array}$ \\
\hline
\end{tabular}


No quesito prova de títulos, o certame de 2003 promoveu relevante alteração no que diz respeito à aproximação da seleção pública com a identificação do profissional capaz de conferir maior eficiência nas ações governamentais, pontuando valores adicionais aos candidatos que comprovassem exercício de cargo ou função nas áreas de opção, em âmbito público ou privado.

Na prova de títulos do concurso relativo ao ano de 2005, a banca examinadora incluiu pontuação para candidatos com especialização lato-sensu, além de pontuação para cada ano de experiência profissional nos setores público ou privado, relacionadas ao exercício de atividades associadas à gestão governamental, privilegiando candidatos possuidores de bagagem profissional relacionada à gestão, indicando um caráter mais técnico na seleção.

Sobre a cobrança de conhecimentos relativos ao tema políticas públicas, como nas provas anteriores, praticamente não há menção no rol de conteúdos de provas objetivas, mas de forma singela, dentro do tema Teoria Política, há a indicação de conteúdo relativo à "formação da agenda, formulação, implementação e avaliação", determinando que, no 9 o processo seletivo, o conhecimento relativo ao ciclo de políticas surgisse pela primeira vez entre as objetivas, tema esse enquadrado no Quadro 2 como fundamental ao desenvolvimento das atribuições legais de gestão.

No quesito prova discursiva, os avanços foram significativos quanto à aproximação de temas pertinentes às atribuições. Segundo o edital determinava, o candidato deveria comprovar conhecimentos em tipologias de políticas, ciclo de políticas públicas, os modelos de análise, atores envolvidos e arenas decisórias, todos conhecimentos destacados como essenciais ao desenvolvimento das atribuições de gestor.

Após quase três anos, a nova seleção aconteceu somente no ano de 2008, com vagas destinadas para Gestão Governamental ou Políticas Públicas. O tema Administração Pública volta como integrante das provas de conhecimentos gerais, mas a principal novidade é percebida no elenco de temas de conhecimentos especializados, de modo que, após quase 20 anos de carreira, verifica-se a cobrança sobre políticas públicas e gestão governamental nas provas objetivas, inclusive sendo solicitado pela primeira vez o "Conceito de Política Pública" no rol de conteúdos exigidos. A discursiva também foi modificada, versando sobre "Desafios para Formulação, Implementação e Acompanhamento de Políticas Públicas", aproximando significativamente ambas as provas daqueles conhecimentos destacados como fundamentais ao profissional que almeja ingressar nos quadros do serviço público no cargo de gestor governamental.

Na seleção seguinte, do ano de 2009, um retrocesso: as áreas de opção da carreira foram suprimidas e com elas a exigência de conhecimentos relativos ao 
tema políticas públicas nas provas objetivas, sendo cobrado apenas "a formação da agenda, processos decisórios e problemas da implementação" dentro do tema Ciência Política, representando uma barreira na identificação de profissionais com arraigados saberes teóricos sobre políticas públicas.

Na prova discursiva, a exigência foi mantida. O conhecimento sobre as políticas deveria ser comprovado em uma dissertação e uma análise de caso, envolvendo a gestão governamental, nos quais seriam avaliados a capacidade de argumentação, a lógica do pensamento, o alinhamento ao tema e a cobertura dos tópicos apresentados. Na prática, a questão relativa à análise de caso não demandou dos candidatos uma análise propriamente dita, nem mesmo a apresentação de alternativas, já que nenhum problema foi apresentado. Ao candidato bastava desenvolver um texto em que abordasse a mudança organizacional, instrumentos gerenciais contemporâneos e planejamento estratégico no âmbito público, determinando a fragilidade das seleções na convergência com as atribuições previstas ao gestor.

\section{0 último processo seletivo}

Quando da idealização do processo seletivo de 2013, a Secretaria de Gestão, em parceria com a Escola Fazendária, realizou uma análise das seleções pregressas a fim de identificar os pontos frágeis e estabelecer novos critérios que determinassem o aprimoramento do processo de identificação do profissional com o perfil esperado pela administração pública.

Essa análise resultou em alterações nos requisitos de seleção. Alguns temas foram inclusos na relação de conteúdos das provas objetivas, a exemplo do contexto da Realidade Brasileira, em que o candidato deveria responder questões relativas à desigualdade social e suas causas, atendimento dos serviços básicos, problemas do crescimento urbano, infraestrutura, educação, política econômica, enfim, uma visão ampla dos problemas de maior recorrência enfrentados pelo Estado.

Em relação às provas objetivas, optou-se pela baixa cobrança de percentual para aprovação nessa etapa, como forma de conduzir uma maior quantidade de candidatos à prova discursiva, cujo formato havia sido alterado em relação às demais.

Para desenvolver a questão, o candidato deveria analisar o texto sobre políticas de erradicação do trabalho escravo no Brasil, relatar sua compreensão sobre a racionalidade substantiva como prática de gestão governamental e, ao final, apresentar estratégias para esse desafio enfrentado pelo Ministério Público do Trabalho, o que, na percepção dos elaboradores, demandaria a junção de conhecimento teórico e vivência prática para resolução e apresentação de alternativas viáveis. 
Ainda como forma de assegurar o ingresso de profissionais com vasta experiência gerencial, a pontuação para cada ano de exercício de atividade gerencial passou de 1,6 para 15 pontos, representando aos candidatos experientes a possibilidade de ter sua nota majorada, determinando a intenção da administração pública em valorizar candidatos possuidores de vasto histórico profissional.

Na percepção da Anesp, essa valorização não veio acompanhada de critérios transparentes para contabilização, o que motivou ação judicial com pedido de suspensão do certame devido à existência de irregularidades no edital quanto à forma de aferição da experiência profissional. O Tribunal de Contas da União, por compreender que o edital não apresentava parâmetros objetivos para a banca examinadora proceder à análise da experiência em atividade gerencial, bem assim a atribuição excessiva de pontos à fase de análise curricular dos candidatos, determinou o cancelamento da seleção, fato publicado através da Portaria no 99/ Esaf, no ano de 2015. Desde então, nenhum outro processo seletivo foi aberto.

\section{Reflexões finais}

A investigação realizada neste ensaio teve por objetivo analisar a convergência de propósitos entre as provas de seleção para o cargo de EPPGG e as atribuições legais previstas ao cargo, quais sejam, aquelas relativas à formulação, implementação e avaliação de políticas públicas.

Através da adoção da análise de conteúdo realizada sobre o texto da previsão legal determinada no Decreto no 5.176/04, bem assim nos diversos estudos realizados sobre a carreira do gestor, foram identificadas duas dimensões teóricas básicas, interpretadas como conhecimentos fundamentais a serem exigidos dos candidatos, quais sejam: políticas públicas e administração pública. O suporte literário permitiu identificar ainda as categorias relacionadas às duas dimensões: conceito de políticas públicas, ciclo de políticas, modelos de análise, redes de políticas, modelos teóricos de administração pública e principais reformas administrativas.

A pesquisa documental foi realizada a partir do ano de 1987 ao ano de 2009, correspondente a 11 editais de seleção, emitidos por três bancas examinadoras, nos 28 anos da carreira. O estudo permitiu a identificação de um rito litúrgico determinado por editais que apresentam alterações frequentes nos conteúdos, mas de formatos semelhantes, sem inovações quanto aos formatos das provas para maior eficiência do processo como um todo.

Sobre os conhecimentos, pode-se afirmar que, em todas as seleções realizadas nos primeiros 15 anos de criação da carreira, a vertente principal de conhecimentos específicos exigidos dos candidatos estava fundamentada no tema administração 
pública, em razão da presença recorrente de conteúdos relativos a modelos teóricos da administração pública, bem assim das reformas administrativas (além dos conteúdos considerados como conhecimentos gerais, tais como Língua Portuguesa, Raciocínio Lógico, Direito Constitucional e Administração e Ciência Política, presentes em praticamente todas as seleções públicas).

Acerca da análise de conteúdo para a dimensão teórica políticas públicas, podese afirmar que o tema foi muito pouco explorado na avaliação de conhecimentos de candidatos a profissionais especialistas em políticas públicas. Quando das seleções dos anos 1990, a possível justificativa poderia estar relacionada à preocupação do Estado voltada à implementação da administração pública gerencial e à busca por novas formas de gestão. Mas a partir dos 2000, os conteúdos poderiam ter sido mais profundamente explorados, o que na prática não aconteceu. Somente na 10 a seleção (2008), passam a ser exigidos os conteúdos relativos às políticas públicas nas provas objetivas, momento em que se comemoravam 20 anos da carreira. Essa inexistência de abordagem ao tema central durante muitos anos possivelmente fragilizou o alinhamento entre a seleção pública e a identificação do profissional policompetente na gestão de políticas. Tardiamente a administração pública percebeu a relevância e a necessidade desses conhecimentos por parte dos candidatos, fato que vem sendo aprimorado nas últimas seleções.

No quesito bagagem profissional, o reconhecimento da experiência se deu a partir apenas do 8 o processo seletivo (2003), momento em que a banca reconhece a experiência profissional dos candidatos, pontuando a comprovação de anos de atividade gerencial, valorizando profissionais que poderiam conferir maior eficiência às ações governamentais.

Sobre a compreensão das provas discursivas, foram identificados diversos modelos de avaliação de conhecimentos, entre eles a dissertação, questionamento discursivo, resumo de texto, estudo de caso e desenvolvimento de tema. Este último foi a principal metodologia de avaliação presente em $70 \%$ dos certames, que não converge ao propósito central da seleção, visto que não exige do candidato o empenho para identificação de problemas, apresentação de alternativas, nem mesmo o raciocínio crítico para que a banca examinadora tenha fundamentos robustos para avaliação da capacidade de argumentação dos concorrentes.

Pode-se inferir, com base na análise realizada, que a administração pública, mesmo após 25 anos de criação da carreira, busca o formato mais adequado aos propósitos das seleções públicas com a identificação do profissional com capacidade de agente de transformação. Depreende-se que a convergência de propósitos da seleção como um todo, em relação às atribuições legais, pode ser reforçada à medida que conteúdos fundamentais sejam exigidos nas provas, especialmente 
aqueles destinados à avaliação dos conhecimentos sobre políticas públicas e gestão pública, no que tange aos elementos previstos no Decreto no 5.176/2004, quais sejam, as etapas de formulação, implementação e avaliação de políticas.

Consideram-se ainda essenciais os conhecimentos sobre o processo de produção de políticas públicas, os fatores associados à formação de agenda, modelos de avaliação, análise custo-benefício e abordagens analíticas. Bem assim os aspectos relativos à gestão pública, os instrumentos contemporâneos relacionados aos recursos humanos, mérito, prestação de contas, responsabilização e a ética profissional. A idealização de um processo que seleciona especialistas em políticas públicas com esses núcleos de avaliação pode conferir maior eficiência à avaliação escrita.

Sugere-se a cobrança de questões de maior profundidade, além de aspectos estritamente conceituais, a abordagem às novas práticas de gestão, em que o candidato apresente conhecimento além da literatura, com relação direta às políticas públicas no Brasil e apresentação de alternativas que sinalizem sua capacidade de aprimoramento das ações governamentais.

Sobre as discursivas, recomenda-se a cobrança permanente da análise de casos, por ser a modalidade de avaliação que apresenta um problema, exigindo do avaliado o empenho para identificação, análise de evidências, desenvolvimento de argumentos lógicos, avaliação e proposição de soluções. E que a avaliação seja desenvolvida em parceria com gestores em atividade, para que candidatos sejam demandados a se posicionarem a despeito de situações reais das políticas e gestão brasileiras, e construída sob a ótica de análise crítica.

E, por fim, a manutenção da valorização profissional com pontuação adicional aos candidatos detentores de experiência prévia, cuja contabilização seja acompanhada de critérios claros descritos em edital, com possibilidade de implantação de preenchimento de formulário biográfico no momento da inscrição, que contribua na análise da trajetória dos candidatos, permitindo a maior adequação na alocação dos servidores entre órgãos demandantes. 


\section{Referências bibliográficas}

ABRUCIO, Fernando Luiz. Trajetória recente da gestão pública brasileira: um balanço crítico e a renovação da agenda de reformas. Revista de Administração Pública, Edição Especial Comemorativa 1967-2007, p. 67-86, 2007.

Agencia Española de CoOperación INTERnaCional para el Desarrollo (AECID). Relatório de Aprimoramento da Gestão da Carreira do Especialista em Políticas Públicas e Gestão Governamental. Brasília: Secretaria de Gestão/Ministério do Planejamento, 2009.

AsSOCIAÇÃo NACIONAL dOS ESPECIALISTAS EM POLÍtICAS PÚBlicAS E GeStÃo Governamental (ANESP). Notícias. Brasília, 2014. Disponível em http://anesp.org. br/todas-as-noticias/ Acesso em nov/2014.

Proposta de Regimento para a Carreira de Especialista em Políticas Públicas e Gestão Governamental. Brasília: Anesp, 2009.

BARBOSA, Lívia. Meritocracia à brasileira: o que é desempenho no Brasil? Revista do Serviço Público, Brasília, Ano 47, v. 120, n. 3, set./dez. 1996.

BARDIN, Laurence. Análise de conteúdo. Lisboa: Edições 70, 2010.

BRASIL. Presidência da República. : Câmara de Reforma do Estado. Plano Diretor da Reforma do Aparelho do Estado. Brasília, 1995.

Presidência da República. Decreto no 5.176, de 10 de agosto de 2004. Regulamenta a Carreira de EPPGG e dá outras providências. Brasília, 2004.

Ministério do Planejamento, Orçamento e Gestão (MPOG). Gestão da Carreira de Especialista em Políticas Públicas e Gestão Governamental - EPPGG: documento de referência para a gestão da carreira de EPPGG. Brasília, 2008.

BRESSER-PEREIRA, Luiz Carlos. Da administração pública burocrática à gerencial. Revista do Serviço Público, Brasília, Ano 47, v. 1, jan./abr. 1996.

. Da administração pública burocrática à gerencial. In: BRESSER-PEREIRA, Luiz Carlos; SPINK, Peter Kevin (Org.). Reforma do Estado e administração pública gerencial. Rio de Janeiro: Fundação Getulio Vargas, 1998.

FGV, 2005.

Reforma do Estado e administração pública gerencial. 4. ed. Rio de Janeiro:

CALMON, Carlos Du Pin et al. O modelo dos múltiplos fluxos de Kingdon na análise de políticas de saúde: aplicabilidades, contribuições e limites. Saúde Soc., São Paulo, v. 22, n. 2, p. 511-520, 2013.

CALMon, Paulo Du Pin; CostA, Artur Trindade Maranhão. Redes e Governanças das Políticas Públicas. Revista de Pesquisa em Políticas Públicas, n. 1, p. 1-29, jul. 2013.

CAPELLA, A. C. N. Perspectivas teóricas sobre o processo de formulação de políticas públicas. Revista Brasileira de Informação Bibliográfica em Ciências Sociais, São Paulo, n. 61, p. 25-52, 2006.

CARdoso JúnIOR, José C.; NogueIRA, Roberto P. Ocupação no setor público tendências recentes e questões em aberto. Revista do Serviço Público, Brasília, Ano 62, n. 3, p. 237-260, jul./set. 2011. 
CASTOR, Belmiro Jobim; JosÉ, Herbert Age. Núcleos estratégicos no Estado brasileiro. Revista Paranaense de Desenvolvimento, Curitiba, n. 92, p. 93-111, set.-dez. 1997.

Cheibub, Zairo; MesquitA, Wania Amélia Belchior. Os Especialistas em Políticas Públicas e Gestão Governamental: avaliação de sua contribuição para políticas públicas e trajetória profissional. Brasília: Enap, 2001.

Coelho, Fernando de Souza et al. Especialista em Políticas Públicas e Gestão Governamental: uma descrição da carreira nos estados da Bahia, Goiás, Mato Grosso, Minas Gerais, Rio de Janeiro e São Paulo. Revista Gestão \& Políticas Públicas, São Paulo, v. 1, n. 1, 2011.

CosTA, Frederico Lustosa. Brasil: 200 anos de Estado; 200 anos de administração pública; 200 anos de reformas. Revista de Administração Pública, Rio de Janeiro, v. 42, n. 5, p. 829-974, set./out. 2008.

CRUz, Rachel. Carreiras burocráticas e meritocracia: o impacto do ingresso de novos servidores na última década sobre a dinâmica do preenchimento de cargos em comissão no Governo Federal brasileiro. In: CONSAD DE GESTÃo PúBLICA, 2., Brasília, 2009.

DenhaRdT, Robert B. Teorias da Administração Pública. São Paulo: Cengage Learning, 2012.

EsCola de AdMINISTRAÇÃo FAZENDÁRIA (Esaf). Edital ESAF no 31, de 10 de outubro de 1995. Concurso Público para Provimento de Cargos de Analista de Planejamento e Orçamento e Especialista em Políticas Públicas e Gestão Governamental. Brasília, 1995

. Edital Esaf no 28, de 23 de novembro de 2000. Concurso Público para Provimento de Cargos de APO e EPPGG. Brasília, 2000

Edital Esaf no 87, de 18 de dezembro de 2001. Concurso Público para Provimento de Cargos de APO e EPPGG. Brasília, 2001

. Edital Esaf no 20, de 04 de julho de 2003. Concurso Público para Provimento de Cargos de APO e EPPGG. Brasília, 2003

Edital Esaf no 46, de 15 de julho de 2005. Concurso Público para Provimento de Cargos de APO e EPGG. Brasília, 2005.

. Edital Esaf no 12, de 26 de março de 2008. Concurso Público para Provimento de Cargos de Analista de Planejamento e Orçamento e Especialista em Políticas Públicas e Gestão Governamental. Brasília, 2008.

Edital Esaf no 46, de 18 de junho de 2009. Concurso Público para Provimento de Cargos Especialista em Políticas Públicas e Gestão Governamental. Brasília, 2009.

Edital Esaf no 48, de 06 de junho de 2013. Concurso Público para Provimento de Cargos Especialista em Políticas Públicas e Gestão Governamental. Brasília, 2013. FADUL, Elvia. M.; SOUZA, Antônio Ricardo. Políticas de reformas da administração pública brasileira: uma compreensão a partir de seus mapas conceituais. In: EnANPAD. Anais... Brasília, 2005.

FundAÇÃo CARLOS ChAGAS (FCC). Edital Mare no 3, de 15 de agosto de 1996. Concurso Público para Provimento de Cargos de APO e EPPGG. Brasília, 1996. 
. Edital Mare no 03, de 06 de outubro de 1997. Concurso Público para Provimento de Cargos de APO e EPPGG. Brasília, 1997

FundAÇÃO CENTRO DE FORMAÇÃO DO SERVIDOR PÚBLICO (FUNCEP). Edital para abertura do 1 o processo seletivo para Curso de Políticas Públicas. DOU, 16 de outubro de 1987.

GUEDES, André Teles. Elites estatais e reforma do Estado na Nova República: o projeto Enap e a formação da carreira de gestor governamental no Brasil. Tese de Doutorado apresentada ao Departamento de Sociologia da Universidade de Brasília, Brasília, 2012.

KINGDON, John W. Agendas, alternatives and public policies. 2. ed. Nova York: Longman, 1995.

LONGO, Francisco. A consolidação institucional do cargo de dirigente público. Revista do Serviço Público, Brasília, Ano 54, n. 2, abr.-jun. 2003.

MAIA, Kadma et al. Nova gestão pública e motivação no serviço público: a carreira de EPPGG como alternativa para as disfunções burocráticas. Revista Gestão Pública: Práticas e Desafios, Recife, v. III, n. 6, dez. 2012.

MARIA, Carmen. Meritocracia à brasileira: a trajetória da carreira dos gestores governamentais. Dissertação de Mestrado apresentada ao Curso de Pós-Graduação em Administração Pública e Governo da Easp/Fundação Getúlio Vargas, São Paulo, 2000.

MAtiAs-Pereira, José. Administração Pública Comparada: uma avaliação das reformas administrativas do Brasil, EUA e União Europeia. Revista Brasileira de Administração Pública, Rio de Janeiro, v. 42, n. 1, p. 61-82, jan.-fev. 2008.

. Curso de Administração Pública. São Paulo: Atlas, 2008a.

MoNTEIRO, Lorena. Reforma da administração pública e carreira dos Estados: o caso do Especialistas em Políticas Públicas e Gestão Governamental do Poder Executivo federal. Revista de Administração Pública, Rio de Janeiro, Ano 47. n. 5, p. 117-143, set./out. 2013.

PAES de PAUlA, Ana Paula. Administração pública brasileira: entre o gerencialismo e a gestão social. Revista de Administração de Empresas, São Paulo, v. 45, n. 1, p. 36-49, jan./mar. 2005.

PEDRoso, Marcel. Racionalidade limitada e uso de informações técnicas em modelos de análise de políticas públicas: proposições sobre a perspectiva integradora da Análise Multicritério de Decisão Espacial Construtivista. Revista de Pesquisa em Políticas Públicas, Brasília, n. 2, p. 59-80, dez. 2013.

Procopiuck, Mario. Políticas públicas e fundamentos da administração pública: análise e avaliação, governança e redes de políticas e administração judiciária. São Paulo: Atlas, 2013.

ReIS, Maria Stela; FerRarezı, Elizabete; Antico, Cláudia. A realidade de governo como matéria-prima na capacitação de servidores públicos na Escola Nacional de Administração Pública no Brasil. In: CLADEA, 17., 2012. Anais... Cartagena, Colômbia: Clad, 2012. 
RuA, Maria das Graças. Análise das Políticas Públicas: Conceitos Básicos - Aprender UnB. In: RUA, Maria das Graças. Brasília, 2009. Disponível em: https://aprender. ead.unb.br > pluginfile.php > mod_folder > content > Aná...Acesso em: fev/2017.

SANTOS, Luiz; CARDoso, Regina. A experiência dos gestores governamentais no Governo Federal do Brasil. In: Congresso INTERnACIONAL Del CLAD, 5., 2000. Anais... São Domingo, República Dominicana: Clad, 2000.

SECCHI, Leonardo. Modelos organizacionais e reformas da administração pública.

Revista de Administração Pública, Rio de Janeiro, v. 43, n. 2, p. 347-69, mar./abr. 2009.

SILVA, Lucas Lopes. A Câmara de Políticas de Gestão, Desempenho e Competitividade: uma nova estratégia para a política federal de gestão pública. In: CONSAD DE GESTÃo PúBLICA, 7., 2014, Brasília, DF.

SouzA, Celina. Políticas públicas: uma revisão da literatura. Sociologias, Porto Alegre, ano 8, n. 16, p. 20-45, jul./dez. 2006.

TORRES, Marcelo Douglas de Figueiredo. Fundamentos da Administração Pública Brasileira. Rio de Janeiro: Ed. FGV, 2012

WEBER, Max. Economia e sociedade: fundamentos de sociologia compreensiva. Vol. 1. 3. ed. Brasília: Ed. UnB, 1994.

\section{Rosane Maria Pio Silva}

Universidade de Brasília (UnB), professora Adjunta do Departamento de Ciências Contábeis e Atuariais, doutora em Administração com ênfase em Administração Pública pela Universidade de Brasília, mestre em Ciências Contábeis pela Universidade de Brasília. Especialista em MBA Controller pela Universidade de Brasília, bacharel Graduação em Contabilidade pela UniDF/DF. Contato: rosanemaria.pio6@gmail.com

\section{Andréa de Oliveira Gonçalves}

Universidade de Brasília (UnB), professora Associada da Universidade de Brasília, Departamento de Ciências Contábeis e Atuariais, Programa de Pós Graduação em Ciências Contábeis (PPGCont), doutora em Integração da América Latina pela Universidade de São Paulo, mestre em Administração Pública pela Universidade Federal do Rio Grande do Sul, bacharel em Ciências Sociais pela Universidade Vale do Rio Doce/MG. Contato: andreagon@unb.br 